\title{
The health impacts of dietary sodium and a low-salt diet
}

\author{
Authors: Rebecca J Suckling ${ }^{\mathrm{A}}$ and Pauline A Swift ${ }^{\mathrm{B}}$
}

High salt intake is now endemic worldwide. It contributes to the generation and maintenance of high blood pressure, which is now the biggest risk factor for global disease. There is now compelling evidence to support salt reduction in hypertensives and a substantial body of evidence to support salt reduction in the general population to reduce risk of death from cardiovascular disease. In specific diseases such as heart failure and chronic kidney disease, guidelines support the World Health Organization target for reduced salt intake at $5 \mathrm{~g}$ daily. Achieving a diet that is lower in salt has challenges, but is more likely to be achieved through salt reduction strategies particularly focused on processed food and through educational programs. To be effective, these interventions require collaboration between industry, health agencies and governments.

\section{Introduction}

For several million years, humans ate very little salt - less than $0.25 \mathrm{~g} /$ day. Salt was introduced as a method to preserve food and this was transformational for civilised societies. ${ }^{1}$ Initially the advent of refrigeration led to a reduction in salt intake; however subsequently the intake of salt has increased and is now estimated to be between 9 and $12 \mathrm{~g}$ /day in most countries worldwide, significantly more than our evolutionary ancestors. ${ }^{1,2}$ This global habituation of salt consumption is of great concern as it is linked to high blood pressure and increased risk of cardiovascular disease, as well as gastric cancer, renal stone disease and osteoporosis. $^{1}$

In specific diseases, the evidence to reduce salt intake is compelling, at least to levels that are suggested by guidelines, if not lower. ${ }^{1,3,4}$ However adherence to salt restriction is poor, even in clinical trials with motivated patients. This is at least in part due to the high prevalence of salt in food, in particular baked and processed food, making it difficult for patients to achieve the reduction that they need to gain clinical benefit. ${ }^{1}$ In this review we have focused on the evidence for lowering

Authors: A consultant nephrologist, South West Thames Renal and Transplantation Unit, Epsom and St Helier University Hospitals NHS Trust, Carshalton, UK; ${ }^{\mathrm{B}}$ consultant nephrologist, South West Thames Renal and Transplantation Unit, Epsom and St Helier University Hospitals NHS Trust, Carshalton, UK salt intake for the general population and in groups with cardiovascular and renal disease.

\section{Salt and high blood pressure}

High blood pressure is the leading risk factor for global disease and has the greatest impact of all risk factors on cardiovascular disease, with non-optimal blood pressure accounting for two-thirds of stoke and one-half of ischaemic heart disease. ${ }^{5}$ Evidence from genetic, epidemiological, migrational and interventional studies contribute to the compelling evidence that salt intake elevates population blood pressure. ${ }^{1}$ The largest epidemiological study of salt and blood pressure, the INTERSALT study, included 10,079 individuals from diverse populations and found a strong positive relationship between sodium intake and blood pressure that persisted even when four populations with very low salt intake were excluded, with an increase of $6 \mathrm{~g} /$ day in salt intake estimated to elevate systolic blood pressure by $9 \mathrm{mmHg}$ over 30 years. ${ }^{6}$ More recent studies EPIC-Norfolk and INTERMAP - support these findings.,

Lowering salt intake reduces blood pressure. An updated systematic review of studies where salt was reduced by $4.4 \mathrm{~g} /$ day for at least 4 weeks found that systolic blood pressure was reduced by $4 \mathrm{mmHg}$ and diastolic blood pressure by $2 \mathrm{mmHg}$. This study found that the effects on blood pressure continued below levels currently suggested by international guidelines. This dose-dependent relationship is supported by 2 independently conducted double blinded randomised controlled studies of different levels of salt intake (12, 6 and $3 \mathrm{~g}^{10}$ and 8,6 and $4 \mathrm{~g}^{11}$ ) where the lowest salt reduction reduced blood pressure to the lowest levels.

\section{Salt intake and its relationship to cardiovascular disease}

High salt intake is likely to contribute to cardiovascular risk primarily through its effects on blood pressure, as well as through blood pressure independent effects on arterial stiffening and albuminuria. ${ }^{1}$ The actual effect of lowering population salt intake on cardiovascular outcomes has been more controversial. Available evidence from epidemiological studies is largely supportive. Public health strategy in the UK has successfully achieved a $15 \%$ reduction in salt intake from 2003 to 2011. This has been achieved through partnership with industry reducing salt content. ${ }^{12}$ Several recent cohort studies have found a J-shaped association between urinary sodium excretion and a composite of major cardiovascular events 
and death. ${ }^{13}$ While this has led to concern about the effect of lowering population salt intake, a review of available cohort studies found inconsistencies in the relationship between sodium intake, with 13 finding a direct relationship, 8 with an inverse relationship and 2 with a J-shaped relationship. All but 1 had inherent methodological limitations which could change the direction of the relationship, including reverse causality and systematic error, and from this the true relationship remains unclear. ${ }^{14}$ While there are limited interventional studies of salt reduction and cardiovascular disease, a metaanalysis of available studies found that a modest reduction in salt intake lowered cardiovascular events. ${ }^{15}$ When individuals who participated in the Trial of Hypertension Prevention I and II were followed up subsequent to the trial completion, those randomised to the low salt arm had a $25 \%$ reduction of cardiovascular events, despite receiving no further dietary advice after completing the study. ${ }^{16}$ It remains appropriate to endorse the current guidelines on salt reduction to prevent cardiovascular events, with the National Institute for Health and Care Excellence endorsing salt reduction as the primary public health strategy for the prevention of cardiovascular disease. $^{3}$

\section{Salt restriction and heart failure}

Haemodynamic changes associated with heart failure lead to increased neurohumoral activity, with a vicious circle of sodium and water retention despite a volume overloaded state. While restricting salt intake is established practice in the management of heart failure, the evidence remains limited to observational studies and small randomised controlled trials of salt restriction, often with additional therapeutic interventions. ${ }^{17-20}$ Given the lack of robust evidence, it is not surprising that, despite being recommended by all current clinical guidelines, there is no consensus on what level of salt restriction would be appropriate. However, restricting salt intake to $5 \mathrm{~g}$ /day, levels recommended by the World Health Organization (WHO) for the general population, is a safe, practical and modest intervention, likely to be of benefit and with no evidence of harm. Individuals on high-dose

\section{Key points}

Salt intake is an important contributor to the development of high blood pressure.

Salt reduction lowers blood pressure effectively in hypertension.

Public health strategies to lower salt are key for reduction in cardiovascular disease.

High salt intake reduces the effectiveness of key medications, including angiotensin-converting-enzyme inhibitors.

The best estimate of salt intake is a $24-\mathrm{h}$ urine collection.

KEYWORDS: Salt intake, sodium, hypertension, cardiovascular disease, heart failure, chronic kidney disease diuretics will require judicious monitoring of fluid balance when implementing a low salt diet, and adjustment of diuretic therapy may be necessary to ensure that they do not become fluid depleted. ${ }^{21}$

\section{Salt and the kidney}

The kidney is the primary regulator of sodium balance and plays a central role in long-term blood pressure regulation. Chronic kidney disease (CKD) is common, affecting up to $13 \%$ of adults. ${ }^{22}$ The vast majority of patients with CKD do not progress to end-stage kidney disease, and the major risk for individuals with CKD is cardiovascular disease, as it is a potent and independent risk factor for cardiovascular death. ${ }^{23}$ Progressive CKD leads to increasing prevalence of hypertension, which often requires multiple medical therapies to gain adequate control. Individuals are more susceptible to the effects of high salt intake due to reduced renal sodium excretion. Managing high blood pressure is a cornerstone of CKD management, with the aim of reducing both risk of CKD progression and cardiovascular disease. ${ }^{4,24}$ Evidence suggests that lowering salt intake will be of benefit in CKD, reducing proteinuria and urinary albumin excretion, as well as enhancing the antiproteinuric and antihypertensive effects of blockers of the renin-angiotensin system. ${ }^{25,26} \mathrm{~A}$ recent review of interventional studies in CKD concluded that there was evidence that salt reduction lowered blood pressure in patients with CKD, but acknowledged that there was an overall lack of studies in this patient group. ${ }^{27}$

\section{Challenges to salt reduction}

Dietary behaviour for salt avoidance is influenced by a number of factors, including availability, cost and accessibility of lower salt options, perceived reduction in palatability of low-salt

\section{Box 1. Estimating salt intake and sodium content.}

\section{How to convert sodium to salt \\ $>2 \mathrm{~g}$ sodium is equivalent to $5.1 \mathrm{~g}$ salt (sodium chloride) \\ $>100 \mathrm{mmol}$ sodium chloride equals $5.8 \mathrm{~g}$ salt \\ $>1 \mathrm{mmol}$ sodium equals $23 \mathrm{mg}$ sodium \\ > $1 \mathrm{~g}$ sodium chloride contains $390 \mathrm{mg}(17 \mathrm{mmol})$ of sodium}

\section{How to estimate daily consumption of salt}

Use a single 24-h urine collection:

$>$ Discard the first voided urine on waking on the day of collection.

> Collect all voided urine up to and including the first void the following morning.

$>$ Record the time at the beginning and the end of the urine collection.

$>$ Suspect inaccurate urine collection in the following circumstances:

- urine creatinine $<4 \mathrm{mmol} /$ day for women or $<6 \mathrm{mmol} /$ day for men

- collection volume $<500 \mathrm{~mL}$ for both sexes

- extreme outliers for urinary creatinine.

$>24$-h sodium excretion $=$ concentration of sodium in urine ( $\mathrm{mmol} / \mathrm{L}) \times$ urinary volume (L/day)

$>$ To convert from mmol to $\mathrm{g}$ divide by 17 
Box 2. Resources for professionals and patients.

\section{Internet resources}

British Heart Foundation: www.bhf.org.uk

British Hypertension Society: www.bhsoc.uk

Blood Pressure Association: www.bloodpressureuk.org

Consensus Action on Salt and Health (CASH):

www.actiononsalt.org.uk

2. Groups concerned with salt and its effects on health. Professional and patient resources available.

World Action on Salt and Health (WASH):

www.worldactiononsalt.com

International arm of CASH with professional and patient resources available.

World Hypertension League: www.worldhypertensionleague. org/index.php/j-stuff/dietary-salt-reduction

Non-profit organisation dedicated to the prevention and control of hypertension at the population level. Has extensive resources including slide presentations and a fact sheet (http://onlinelibrary.wiley.com/doi/10.1111/jch.12402/epdf).

Hypertension TALK: Provides a weekly MEDLINE search of articles related to dietary sodium (www.hypertensiontalk.com/ science-of-salt-weekly/)

\section{Food Switch app}

FoodSwitch is a free UK only download from iTunes or Google Play

> iTunes: https://itunes.apple.com/gb/app/foodswitch-uk/ id804442303? $\mathrm{mt}=8$

> Google Play: https://play.google.com/store/apps/ details?id=uk.co.bupa.foodswitch\&hl=en_GB

food, as well as educational limitations such as lack of perceived benefit or ability to identify lower salt foods. ${ }^{27}$ With only $15 \%$ of salt consumed added at the table and $80 \%$ added by the food industry, it requires motivation to reduce salt effectively. Pressure from an action group formed of specialists (Consensus Action on Salt and Health) has been effective at working with the government and the food industry to agree voluntary reduction in the salt content by levels of $10-15 \%$, levels which are not detectable by consumers. ${ }^{1}$ It is important to reassure individuals that as salt intake reduces, taste buds become more sensitive to salt within a few months. Once taste buds have adjusted, individuals find they prefer food with lower salt content. ${ }^{28}$ Monitoring adherence to a low-salt diet also has its challenges with measurement of 24-hour urinary sodium excretion; the most accurate way to determine average daily salt intake (Box 1). A careful dietary history may be helpful in identifying highly salty foods. Useful resources for professionals and patients can be found in Box 2 .

\section{Conclusions}

High salt intake is endemic worldwide and contributes to the generation and maintenance of high blood pressure, the biggest risk factor for global disease. There is now compelling evidence to support salt reduction to lower blood pressure and a substantial body of evidence to support salt reduction in the general population to reduce risk of death from cardiovascular disease. In specific diseases such as heart failure, diabetes and CKD, guidelines support the WHO target for reduced salt intake at $5 \mathrm{~g} /$ day, although the evidence is perhaps only now catching up with the guidance. Further evidence from population studies would be helpful to reinforce the current guidance, but intervention studies at that level are not likely to be supported by either industry or government. Collaborations with the food industry, health agencies and government will be necessary to support salt reduction strategies.

\section{References}

1 He FJ, MacGregor GA. A comprehensive review on salt and health and current experience of worldwide salt reduction programmes. J Hum Hypertens 2009;23:363-84.

2 World Health Organization. Salt reduction. Fact sheet No 393 Geneva: WHO, September 2014. Available online at www.who.int/ mediacentre/factsheets/fs393/en/ [Accessed 5 November 2015].

3 National Institute for Health and Care Excellence. Prevention of cardiovascular disease. Guideline PH25. London: NICE, June 2010.

4 Kidney Disease: Improving Global Outcomes (KDIGO) CKD Work Group. KDIGO 2012 clinical practice guideline for the evaluation and management of chronic kidney disease. Kidney Int 2012;Suppl:1-150.

5 World Health Organisation. The world health report 2002 - reducing risks, promoting healthy life. Geneva: WHO, 2002. Available online at www.who.int/whr/2002/en/index.html [Accessed 5 October 2015].

6 Elliott P, Stamler J, Nichols R et al. Intersalt revisited: further analyses of 24 hour sodium excretion and blood pressure within and across populations. Intersalt Cooperative Research Group. BMJ 1996;312:1249-53.

7 Zhou BF, Stamler J, Dennis B et al. Nutrient intakes of middle-aged men and women in China, Japan, United Kingdom, and United States in the late 1990s: The INTERMAP Study. J Hum Hypertens 2003;17:623-30.

8 Khaw K, Bingham S, Welch A et al. Blood pressure and urinary sodium in men and women: the Norfolk Cohort of the European Prospective Investigation into Cancer (EPIC-Norfolk). Am J Clin Nutr 2004;80:1397-403.

9 He FJ, Li J, MacGregor GA. Effect of longer term modest salt reduction on blood pressure: Cochrane systematic review and metaanalysis of randomised trials. BMJ 2013;346:1325.

10 MacGregor GA, Markandu ND, Sagnella GA, Singer DRJ, Cappuccio FP. Double-blind study of three sodium intakes and long-term effects of sodium restriction in essential hypertension. Lancet 1989;2:1244-7.

11 Sacks F, Svetkey L, Vollmer W et al. Effects on blood pressure of reduced dietary sodium and the dietary approaches to stop hypertension. N Engl J Med 2001;344:3-10.

12 MacGregor GA, He FJ, Pombo-Rodrigues S. Food and the responsibility deal: how the salt reduction strategy was derailed. $B M J$ 2015;350:h1936

13 O’Donnell M, Mente A, Rangarajan S et al. Urinary sodium and potassium excretion, mortality, and cardiovascular events. $\mathrm{N} \mathrm{Engl} \mathrm{J}$ Med 2014;371:612-23.

14 Cobb LK, Anderson CAM, Elliott P et al. Methodological issues in cohort studies that relate sodium intake to cardiovascular disease outcomes: a science advisory from the American Heart Association. Circulation 2014;129:1173-86.

15 He FJ, MacGregor GA. Salt reduction lowers cardiovascular risk: meta-analysis of outcome trials. Lancet 2011;378:380-3. 
16 Cook N, Cutler J, Buring J et al. Long term effects of dietary sodium reduction on cardiovascular disease outcomes: observational follow-up of the trials of hypertension prevention (TOHP) BMJ 2007;334:885-8.

17 Gupta D, Georgiopoulou VV, Kalogeropoulos AP et al. Dietary sodium intake in heart failure. Circulation 2012;126:479-85.

18 He J, Ogden LG, Bazzano LA et al. Dietary sodium intake and incidence of congestive heart failure in overweight US men and women: first National Health and Nutrition Examination Survey Epidemiologic Follow-up Study. Arch Intern Med 2002;162: 1619-24.

19 Hummel SL DA, Skorcz S, Montoye CK, Koelling TM. Recommendation of low-salt diet and short-term outcomes in heart failure with preserved systolic function. Am J Med 2009;122:1029-36.

20 Paterna S GP, Fasullo S, Sarullo FM, Di Pasquale P. Normal-sodium diet compared with low-sodium diet in compensated congestive heart failure: is sodium an old enemy or a new friend? Clin Sci (Lond) 2008;114:221-30.

21 He FJ, Burnier M, MacGregor GA. Nutrition in cardiovascular disease: salt in hypertension and heart failure. Eur Heart J 2011;32:3073-80

22 NHS Information Centre. Health Survey for England 2009: health and lifestyles. London: NHS Information Centre, 2009. Available online at www.ic.nhs.uk/webfiles/publications/003_Health_ Lifestyles/hse09report/HSE_09_Summary.pdf [Accessed 5 October 2015].
23 Hallan S, Dahl K, Oien C et al. Screening strategies for chronic kidney disease in the general population: follow-up of cross sectional health survey. BMJ 2006;333:1047.

24 National Institute for Health and Care Excellence. Chronic kidney disease: early identification and management of chronic kidney disease in adults in primary and secondary care. CG182. London: NICE, 2014.

25 MacGregor GA, Markandu ND, Singer DRJ et al. Moderate sodium restriction with angiotensin converting enzyme inhibitor in essential hypertension: a double blind study. BMJ 1987;294:531-4.

26 Houlihan CA, Allen TJ, Baxter AL et al. A low-sodium diet potentiates the effects of losartan in type 2 diabetes. Diabetes Care 2002;25:663-71.

27 McMahon EJ, Campbell KL, Mudge DW, Bauer JD. Achieving salt restriction in chronic kidney disease. Int J Nephrol 2012;2012:10.

28 Cappuccio F, Capewell S. Facts, issues and controversies in salt reduction for the prevention of cardiovascular disease. Functional Food Rev 2015; 7:41-61.

Address for correspondence: Dr RJ Suckling, Renal Unit, Epsom and St Helier University Hospitals NHS Trust, Wrythe Lane, Carshalton SM5 1AA, UK.

Email: rebecca.suckling@esth.nhs.uk

\section{NCGC $\mid$ National Clinical

\section{New to systematic reviewing, or need to improve your critical appraisal skills?}

Our intensive 1-day courses will introduce you to the key principles of critical appraisal and systematic reviewing, and equip you with the basic skills to put your knowledge into practice.

> Introduction to critical appraisal

> Systematic reviews and meta-analysis in action

Discount available if both courses are booked together.

'Informative and practical'

Dr Rajeswari Ramaraj

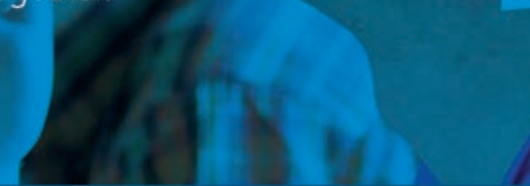

